\title{
Financiamiento de las escuelas elementales oficiales de Tlaxcala: una interpretación de la legislación educativa, 1857-1898
}

\author{
The Financing of Official Elementary Schools \\ in Tlaxcala: An Interpretation \\ of Educational Legislation, 1857-1898
}

María de Lourdes Solares Ramos

Escuela de Educación Normal José Santos Valdés

solares.lourdes@gmail.com

\begin{abstract}
Resumen
En el financiamiento de las escuelas elementales de Tlaxcala de 1857 a 1898 es posible mirar la paulatina centralización de la educación en manos del estado. En este artículo reconstruyo la política fiscal de las escuelas, a través del análisis de la legislación, en el que pongo especial atención al origen de los fondos de instrucción pública, los actores institucionales que los administraron y cómo se invirtieron. Las sucesivas reformas introducidas en la legislación sugieren que, en un principio, hubo una gestión local de los pueblos y ayuntamientos sobre los recursos económicos. Sin embargo, en 1882, con la llegada de los gobernadores porfiristas, el control local fue desplazado y los fondos de instrucción pública fueron recolectados y distribuidos por los representantes del gobierno estatal: el tesorero, el prefecto político y el gobernador.
\end{abstract}

Palabras clave: Tlaxcala, siglo XIX, municipio, centralización, financiamiento.

\section{Abstract}

It is in the financing of elementary schools in Tlaxcala from 1857 to 1898 that one can look at the gradual centralization of education in the hands of the state. In this article, I reconstruct the fiscal policy of schools through the analysis of legislation, in which I pay special attention to the origin of public education funds, the institutional actors that administered them and how they were invested. The successive introduced reforms in the legislation suggest that, initially, the economic resources were locally managed by the towns and municipalities. However, in 1882, with the arrival of the Porfirian governors, the local control was displaced, and the funds of public instruction were collected and distributed by the representatives of the state government: the treasurer, the political prefect and the governor 


\section{Introducción}

Los términos de centralización y federalización de la educación, como señala Alberto Arnaut (1998), adquieren su significado "según la coyuntura en la cual se usa[n]", y el sentido que les otorgan los historiadores también cambia en el tiempo y el espacio. El libro coordinado por María del Carmen Pardo (1999), por ejemplo, los utiliza respecto de las formas de control que ejerce el gobierno federal sobre el ámbito educativo de los estados, desde el porfiriato hasta los años noventa. En tanto, Alberto Arnaut (1998) concede un lugar especial a las discusiones suscitadas en el porfiriato sobre la centralización de la educación (en los congresos educativos, en la prensa y en los foros pedagógicos). En esas discusiones, los políticos buscaban que la federación se encargara de las escuelas del país, debido, entre otras cosas, a que los municipios no podían financiar los centros de enseñanza. Fue hasta 1921 cuando la Secretaría de Educación Pública (SEP) empezaría a implementar dicha centralización al absorber algunas escuelas de los estados.

Según Arnaut, los debates porfirianos tendientes a la centralización se dieron, entre otras cosas, por los problemas financieros de los municipios, que repercutieron directamente en la apertura y funcionamiento de las escuelas. Sin embargo, cabe preguntarse qué pasó en los estados sobre la situación hacendaria de los municipios. Pasar del análisis macrohistórico de Arnaut al análisis regional permitirá descubrir que, detrás del desarrollo del sistema federal educativo, hay situaciones particulares que muchas veces se desvanecen en las historias nacionales.

En el estado de Tlaxcala, Elsie Rockwell contempla al municipio en la construcción del sistema escolar tlaxcalteca. En su estudio identifica que antes, durante e incluso después de la Revolución los ayuntamientos tuvieron un papel predominante en la gestión de la instrucción pública, a pesar de los años de sumisión ante el prefecto político (2007). En cuanto al Estado de México, también se han desarrollado varios estudios que reflejan las formas en que los municipios sostenían las escuelas y sus vínculos con los gobiernos estatal y federal. El consenso general de estas investigaciones es que, durante el siglo XIX, los ayuntamientos tuvieron que soportar las cargas económicas de las escuelas impuestas por los gobiernos estatales, como la "contribución directa", conocida también como "impuesto personal" (López, 2013; Becerril, 2013, Padilla, 2013; Bustamante, 2015). Para el caso de Puebla, Ariadna Acevedo $(2015 ; 2006)$ hace un recorrido histórico, desde el porfiriato hasta la posrevolución, de la herencia de los municipios en su sostenimiento, su relación con el estado y la federación.

Por otra parte, para entender la tradición de la gestión local de las escuelas elementales por los municipios y los pueblos, han resultado sumamente esclarecedores los estudios de Dorothy Tanck (1999; 2002) sobre la educación en el periodo virreinal. En "El gobierno municipal y las escuelas de primeras letras en el siglo XVIII mexicano" (1999), Tanck reconstruye las formas de 
financiamiento, los salarios de los maestros y la participación de varios grupos en el sostenimiento de escuelas gratuitas.

El presente artículo intenta sumarse a los trabajos regionales para reconocer que, durante el porfiriato, hubo una centralización educativa en Tlaxcala. Aplico el concepto de "centralización" para designar el control del gobierno tlaxcalteca sobre la gestión de las escuelas; asimismo, intento reconstruir el financiamiento de las escuelas, particularmente el origen de los fondos de instrucción pública, los actores institucionales que los administraron y cómo se invirtieron en Tlaxcala en la segunda mitad del siglo XIX.

Para cumplir mis objetivos, recurro, en primer lugar, a las fuentes escritas del ramo educativo: leyes y reglamentos. Sin embargo, considerando que las decisiones políticas influyen directamente en el quehacer educativo, amplío mis fuentes a los documentos políticos y de orden financiero. La intención de extender mi análisis a la política es darle un giro social a las leyes y, así, hacer sensible la mirada al contexto sociopolítico en que se publicaron. ${ }^{1}$

En este cruce de información entre educación y política, mostraré que, de 1857 a 1898, hubo dos tendencias fiscales en la política educativa de Tlaxcala: primero, la gestión local y la centralización estatal. La primera comenzó en 1857, cuando, después de un largo proceso de defensa por no ser anexada a Puebla, Tlaxcala logró ser un estado libre y soberano, y logró entonces legislar y reglamentar el ramo educativo. En pocos años, los políticos pudieron dar forma a las leyes que legitimaron a los vecinos y a los ayuntamientos para crear, manejar y distribuir los fondos de instrucción pública. La segunda tendencia inició en 1882, cuando una serie de sucesivas reformas permitieron que el gobierno estatal se encargara de concentrar y redistribuir estos recursos, destinados sobre todo a sueldos de los maestros. Dicho cambio en la política fiscal coincidió con el desarrollo del régimen porfirista en el estado. Las leyes aprobadas por el gobierno de Próspero Cahuantzi (1885-1898) impulsaron la intervención directa del gobernador y de los prefectos políticos en el manejo de los fondos de instrucción pública que generaron más dinero (contribución personal, fondos municipales, y un mínimo presupuesto estatal). Los pueblos fueron seriamente castigados al continuar aportando recursos para los fondos, sin poder decidir sobre su destino.

Los textos legislativos que cubren el periodo de estudio son el corpus documental que sustenta este texto: un decreto de la organización de las escuelas (1857), tres constituciones estatales, seis leyes estatales (educativas, municipales y hacendarias) y tres reglamentos (el último con vigencia hasta 1917). Para la reconstrucción de esta historia fue indispensable realizar un cruce de información de toda esta legislación entre sí, y con información política tanto estatal como federal de cada época.

\footnotetext{
${ }^{1}$ Quiero aclarar que la mayoría de mis fuentes escritas son el resultado de un proceso legislativo, a excepción de Decreto núm. 5, y el Reglamento de Instrucción primaria obligatoria en el estado (1898)
} 


\section{Financiamiento de las escuelas: los vecinos y el ayuntamiento (1857-1872)}

Guillermo del Valle perteneció a la generación de políticos liberales formados en las primeras cinco décadas del siglo XIx (Buve, 2010: 47), entre quienes estaban también Manuel Saldaña, Miguel Lira y Ortega, Luis León y Antonio Rojas. En 1855, este grupo, que hizo carrera militar y política, además de desarrollar una lealtad con los pueblos indios del centro de Tlaxcala, apoyó a Del Valle para ser jefe político. Posteriormente, en diciembre de 1856, después de varias décadas de insistir por su autonomía, ante los intentos de Puebla por integrar a Tlaxcala a su administración, el grupo logró que se convirtiera en estado libre y soberano (Buve, 2010: 59). En pocos meses, los liberales, encabezados por Lira y Ortega, lograron dar forma al nuevo estado. En abril de 1857, instalaron el Congreso y, en junio de ese mismo año, nombraron a Guillermo del Valle como gobernador.

Una de las principales prioridades del recién instalado gobierno fue la "legislación de la instrucción primaria" (Verástegui y Pérez, coords., 1990: 373-374). Sin más preámbulos, el gobierno elaboró un decreto para la instrucción primaria. Sin llegar a ser ley, pero con el mismo poder, el Decreto núm. $5^{2}$ (1857) estableció en veintiún artículos las primeras normas del funcionamiento de las escuelas. Con una vigencia de diez años, este documento recuperó lo que en los hechos era evidente: los pueblos tenían décadas de asumir el financiamiento de las escuelas, por lo menos desde finales del siglo XVIII. ${ }^{3}$

El Decreto de 1857 legisló lo que ocurría en la práctica. Se estableció entonces que las siete "Juntas Directivas de Instrucción Primaria"4 estarían integradas por ciudadanos que radicaban en la sección que les atañía, además, debían de gozar de buena reputación moral y edad de veinticinco años. ${ }^{6}$ Dichas juntas elaborarían un plan para definir los fondos destinados a las escuelas, así como el presupuesto de sus gastos y los medios de la recaudación y contabilidad? Los medios para generar dinero para las escuelas no sólo serían planeados por las juntas, sino que el decreto impuso otros fondos que, aparentemente, estaban fuera del alcance de aquéllas. La contribución de Chicontepec es particularmente interesante.

2 "Decreto núm. 5 (1857)", en García y Pérez, coords. (1991: 395-398).

${ }^{3}$ En 1773 , existían 110 pueblos y en todos había un maestro que recibía su sueldo de los naturales, ya sea en reales o en pesos. Además, en algunas ocasiones, los maestros recibían una fanega de maíz (Diligencias practicadas por el Señor Gobernador de la Ciudad de Tlaxcala. En virtud de un superior Despacho de el excelentísimo señor Virrey de esta Nueva España. Febrero 27 de 1773 años, AHET, fondo colonia, siglo xviii, c. 217, exp. 8).

${ }^{4}$ Art. 1, Decreto núm. 5.

${ }^{5}$ El territorio se dividió en siete secciones. En cada una estaba una junta. Las secciones no fueron una división territorial que respondiera a la división política administrativa.

${ }^{6}$ Art. 5, Decreto núm. 5.

${ }^{7}$ Art. 10, Decreto núm. 5. 
En el Decreto, artículo 11, fracción VI, aparece la contribución del 23 de julio de 1823, conocida como "la de Chicontepec", donde se pagaría del producto total o la mitad de la contribución "donde fuera posible y conveniente establecerla". Sin embargo, respecto de este impuesto se sabe poco. La referencia más cercana y anterior al Decreto, para el caso de Puebla, es la investigación de Ariadna Acevedo (2004: 24), quien sugiere que la contribución tuvo su origen en una petición de 1824 (o quizá un poco antes, no es claro) del municipio de Chicontepec para recolectar entre sus habitantes dinero para los gastos municipales. Posteriormente, en 1848, el estado de Puebla retomó esta contribución con el nombre de Chicontepec, para dedicarla exclusivamente a la educación. En el caso de Tlaxcala, la contribución de Chicontepec fue el inicio del impuesto personal que, por lo menos en el decreto, no fue obligatorio. Aparte de este impuesto, hubo otros fondos que probablemente fueron el reflejo del contexto social, político y económico de los pueblos.

El Decreto núm. 5 señalaba que "El aguardiente de caña, vinos y licores procedentes fuera del estado pagarían derechos en la municipalidad donde se consumieran" (art. 12); los "sobrantes de dominicas, donde se aplique a ese objeto" y los que "quieran donar voluntariamente las personas particulares para auxiliar los costos" (art. 11, fracciones III y V). Los fondos que constituyen "los arbitrios y recursos con que cuenta actualmente" y las "sumas que producen los capitales consignados a la instrucción primaria" (art. 11, fracciones I y IV) parecen ser anteriores al decreto, aunque no pueden ser valorados al carecer de más información.

En general, no se sabe cómo se manejaban los diferentes fondos, incluyendo los de las juntas, tampoco se habla de cantidades específicas de cada impuesto. Sin embargo, es casi seguro que todo quedaba en los pueblos administrado por las juntas. Lo que sí es claro es que los fondos se invirtieron únicamente en el pago de los sueldos de los preceptores y "en los gastos que sean indispensables para la asistencia de las escuelas y amigas ya establecidas" y que se establecieran, en lo sucesivo, con excepción del 2 por ciento, sobre su monto total para los gastos de las Juntas Directivas.

En los siguientes diez años, durante la guerra de Reforma, la Intervención Francesa y del Segundo Imperio, no se expidió ninguna ley referente al tema educativo. Fue hasta el mandato de Miguel Lira y Ortega como gobernador juarista (1867-1872) cuando se instalaron nuevas formas políticas de concebir al ayuntamiento y, con ello, se elaboraron varios documentos que hicieron referencia directa entre las autoridades locales y las escuelas. ${ }^{10}$ El gobernador

\footnotetext{
${ }^{8}$ Art. 11, fracción VI, Decreto núm. 5.

${ }^{9}$ El municipio de Chicontepec actualmente pertenece al estado de Veracruz. En ese entonces, perteneció a Puebla.

${ }^{10}$ Reglamento provisional para el gobierno interior de los distritos del Estado. Véanse El Pueblo. Periódico semioficial del gobierno del Estado, agosto de 1867, AHET, Fondo Histórico, sección Periódico Oficial del Estado de Tlaxcala; Constitución del estado de Tlaxcala (1868), "Miguel Lira y Ortega, gobernador", "El Pueblo. Periódico oficial del gobierno del estado", mayo y junio; Ley de instrucción primaria (1868), Miguel Lira y Ortega, gobernador, AHET, Fondo Histórico, sección Periódico Oficial del Estado de Tlaxcala; Ley de Instrucción Primaria (1868), Miguel Lira y Ortega, gobernador,
} 
Miguel Lira y Ortega insistió en la "libertad" e "independencia" del "poder municipal" como algo natural (de por sí) en el gobierno local de los pueblos (Lira y Ortega, 1982: 4375). Él mismo asumió que el ejercicio de la administración de los ayuntamientos se entendía como "atribuciones naturales", en las que incluía "atender las escuelas de primeras, sin descuidar nunca su vigilancia" (Lira y Ortega, 1982: 67-75). Bajo estas condiciones, parecería que las reformas y cambios que hizo Lira y Ortega en el ramo municipal y educativo estuvieron encaminadas, por una parte, a organizar la relación entre el ayuntamiento y la escuela y, por la otra, a sentar las bases de este vínculo. En su administración se legislaron esas "atribuciones naturales" del ayuntamiento sobre la educación.

Las decisiones políticas que introdujo Miguel Lira y Ortega en su gobierno impactaron directamente en la estructura financiera de las escuelas. A partir de 1868, en la Constitución del estado de Tlaxcala, además del Poder Ejecutivo, Legislativo y Judicial, se incorporó al municipio como el cuarto poder. Lira y Ortega reconoció que el ayuntamiento era fundamental en la administración del estado. Tras esta reforma política, se decretaron varias leyes que colocaron al municipio dentro del funcionamiento y gestión de las escuelas. La Ley de instrucción primaria de 1868 dispuso que en las cabeceras de las municipalidades hubiera una "Junta Directiva", compuesta "por lo menos de cinco individuos vecinos de la municipalidad, activos, que sepan leer y escribir, de buenas costumbres y mayores de veinte un años" (art. 5).

Que las Juntas Directivas pasaran a los municipios provocó dos situaciones: la primera, que la participación de los vecinos en las escuelas aumentara por el hecho de que habría tantas juntas como municipios; la segunda es que los ayuntamientos empezaran a elegir a esos veci-

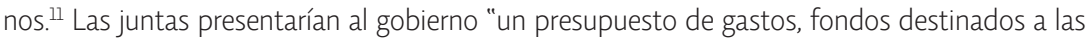
escuelas, o que deban crearse, así como los medios de su recaudación y contabilidad" 12 Por su lado, los ayuntamientos estarían obligados a cubrir los presupuestos mensuales que las juntas les presentaran, sólo en el caso de que "éstas no tengan fondos separados para cubrirlos".13

Conviene diferenciar los "fondos municipales" de los "fondos de instrucción". Los primeros eran definidos por los ayuntamientos en los presupuestos sobre las bases de la Ley de Hacienda Municipal.14 En Tzompantepec, por ejemplo, los fondos municipales consistían en lo recaudado en el tianguis y corral de conejo, "como de las multas que impone el ayunta-

El Pueblo. Periódico semioficial del gobierno del Estado, mayo de 1868, AHET, Fondo Histórico, sección Periódico Oficial del Estado de Tlaxcala; Ley orgánica del poder municipal (1869), Miguel Lira y Ortega, gobernador, AHET, sección Folletería, c.1 5, núm. 3.

${ }^{11}$ Art. 5, Ley de instrucción primaria, 1868.

${ }^{12}$ Art. 6, fracción II, Ley de instrucción primaria, 1868.

${ }^{13}$ Ley Orgánica del Poder Municipal (1869), Miguel Lira y Ortega, gobernador, AHET, sección Folletería, c. 15, núm. 3. Artículo 8, fracción VI.

${ }^{14}$ Art. 8, fracción XIX, Ley Orgánica del Poder Municipal, 1869. 
miento y los ciudadanos alcaldes". ${ }^{15}$ En el municipio de San Bernardino Contla, una parte de los fondos se recaudaron de la extracción de resinas y sacas de madera. ${ }^{16}$

La Ley de instrucción primaria de 1868 contemplaba que las juntas que no llegaran a tener fondos propios recurrirían a los municipales. ${ }^{17}$ La financiación de las escuelas que dependía de los fondos municipales estuvo siempre en riesgo, más con la eliminación de las alcabalas, cuyo ingreso (al menos en buena parte) era usado para la educación primaria. ${ }^{18}$ Algunos municipios alegaban que sus fondos municipales eran inexistentes. Tepeyanco, por ejemplo, decía no tener fondos municipales; en cambio, los fondos destinados a la enseñanza "cubren bien sus exigencias". ${ }^{19}$ En la misma situación estaba Zacatelco, donde los fondos reservados a la instrucción cubrían únicamente los sueldos de los preceptores. ${ }^{20}$ En otros municipios, como Terrenate, "no hubo fondos para la enseñanza pública", sólo fondos municipales, los que formaban únicamente "las contribuciones impuestas para pago de sueldos de los preceptores". 21

Dentro de la Ley de instrucción primaria de 1868, se incluyeron otros fondos de instrucción primaria, "los que tengan consignados o que en lo sucesivo se les consignaren los recursos o arbitrios de que disfruten actualmente"; "lo que dieren los particulares por la educación de sus deudos" y una pensión que pagarán las tabernas en cada municipalidad, desde tres centavos diarios hasta doce y medio las de pulque tlachique, y desde doce y medio hasta veinticinco centavos las de pulque fino". El 6 por ciento que deben producir los terrenos de comunidad adjudicados conforme a las leyes de la materia ${ }^{22}$ es, en esencia, un fondo que se

${ }^{15}$ El Pueblo. Periódico semioficial del gobierno del Estado, 11 de agosto de 1870, AHET, Fondo Histórico, sección Periódico oficial de estado de Tlaxcala.

${ }^{16}$ El Pueblo. Periódico semioficial del gobierno del Estado, 28 de agosto de 1870, AHET, Fondo Histórico, sección Periódico oficial de estado de Tlaxcala.

${ }_{17}$ Art. 6, fracción VI, Ley de instrucción primaria, 1868.

${ }^{18}$ Discursos pronunciados por el presidente del Congreso, C. Lic. Severino Huerta, y el C. Gobernador del Estado, Miguel Lira y Ortega, en la solemne apertura de sesiones extraordinarias de la Cámara, el día 24 de junio de 1868, AHET, Fondo Histórico, sección Periódico Oficial del Estado de Tlaxcala.

${ }^{19}$ El caso del municipio de Tepeyanco. El Pueblo. Periódico semioficial del gobierno del Estado, 21 de mayo de 1870. AHET, Fondo Histórico, sección Periódico Oficial del Estado de Tlaxcala.

20 El Pueblo. Periódico semioficial del gobierno del Estado, sábado 30 de abril de 1870 AHET, Fondo Histórico, Sección Periódico Oficial del Estado de Tlaxcala, AHET, Fondo Histórico, Sección Periódico Oficial del Estado de Tlaxcala.

${ }^{21}$ El Pueblo. Periódico semioficial del gobierno del Estado, 21 de julio de 1870, AHET, Fondo Histórico, sección Periódico Oficial del Estado de Tlaxcala.

22 Art. 9, fracción II, Ley de Instrucción primaria, 1868. "Los Fondos de Instrucción Primaria los integraban los sobrantes de dominicas a donde se apliquen a este objeto - Los bienes mostrencos declarados tales por la autoridad que corresponda - todas las multas que se impongan por las autoridades no teniendo de antemano señalada alguna especial consignación; Una manda forzosa con el mínimo de veinticinco centavos que deberá cobrarse en toda sucesión ex testamento y ab intestado, por los Tesoreros de los ayuntamientos y una pensión que pagarán las tabernas en cada municipalidad, desde tres centavos diarios hasta doce y medio las de pulque tlachique y desde doce y medio hasta veinticinco centavos las de pulque fino". 
constituyó con base en los terrenos comunales que llegaron a llamarse "de instrucción pública" (Rockwell, 2007: 237). El cobro de estos impuestos se haría por las tesorerías municipales.

La suma de todos los impuestos ya mencionados, ya sean los designados a la educación o los municipales, cubrían los gastos de las escuelas. La contribución de Chicontepec, que en otros estados del país ${ }^{23}$ representaba el mayor ingreso para la instrucción, fue cancelada en la Ley de instrucción primaria de 1868. A pesar de la ausencia de la contribución de Chicontepec en las legislaciones, en la práctica, varios municipios recurrían a aquélla. En Nativitas, las "dotaciones" de los establecimientos, "excepto el de la cabecera, se cubrían con la contribución Ilamada Chicontepec, y la de que se recaudaba por fondos municipales". 24 En San Pablo del Monte, este impuesto fue la única fuente de ingresos a los fondos de instrucción, "cuyo producto con dificultad llega semanariamente a cinco pesos". 25 Eliminada la contribución de Chicontepec, el fondo que aportaría la cantidad más grande de dinero fue el 6 por ciento sobre los terrenos de comunidad adjudicados, además de los fondos que la junta y los municipios aportaran. Cabe mencionar que fue en la administración de Lira y Ortega cuando los réditos de las tierras adjudicadas se hicieron visibles en las leyes. Desde 1856, los prefectos políticos estaban facultados para adjudicar terrenos que eran de "comunidad" y que pasaron a la instrucción pública. ${ }^{26} \mathrm{El} 6$ por ciento sobre el valor de la propiedad continuó como una medida fiscal, ${ }^{27}$ por lo menos hasta la revolución.

Respecto a los fondos de instrucción (recaudación y distribución), fueron las Juntas Directivas y los ayuntamientos los encargados por medio de las tesorerías municipales. En cuanto a los rubros en que se invertirían los fondos de instrucción primaria, el artículo 12 de la Ley de instrucción primaria dispuso que fuera en los sueldos de los preceptores y preceptoras, en libros y útiles necesarios "y en cualquier otro gasto indispensable para el sostén de los establecimientos".

\section{Escuelas: obligatoriedad y gratuidad}

El tema principal de la Ley de instrucción primaria de 1868 fue la obligatoriedad de la educación. El artículo $1^{\circ}$ de la ley es muy claro: "la instrucción primaria en el estado es forzosa y todo ciudadano tiene la obligación de recibirla y proporcionarla a su familia". A partir de las

\footnotetext{
${ }^{23}$ Para el caso de Puebla, véase Acevedo (2004); para el del Estado de México, véase García (2013).

${ }^{24}$ El Pueblo. Periódico semioficial del gobierno del Estado, 2 de abril de 1870, AHET, Fondo Histórico, sección Periódico Oficial del Estado de Tlaxcala.

${ }^{25}$ El Pueblo. Periódico semioficial del gobierno del Estado, 14 de mayo de 1870. AHET, Fondo Histórico, sección Periódico Oficial del Estado de Tlaxcala.

${ }^{26}$ Oficio de la prefectura del distrito de Hidalgo, Tlaxcala, 1913. AHET, Fondo Revolución y Régimen Obregonista, sección Justicia y Gobernación, c. 147, exp.38.

27 Supongo que esta medida fue el resultado de la Ley de Desamortización de Fincas Rústicas y Urbanas Propiedad de Corporaciones Civiles y Eclesiásticas.
} 
reformas liberales de mediados del siglo XIX, el financiamiento de escuelas, que desde la época colonial había sido para los vecinos una costumbre y se hacía "voluntariamente", 28 se trasformaría en una cuestión forzosa, es decir, obligatoria para los padres. Éste fue el principio que usó Lira y Ortega para cimentar e impulsar la instrucción primaria. El doble mensaje del artículo primero de la Ley de Instrucción Primaria es particularmente interesante: por un lado, nombraba al Estado como el impulsor para llevar la enseñanza a las familias; por el otro, deslindaba a este de sostener la educación al establecer que la obligación de hacerlo era de los ciudadanos. Entonces los niños recibirían instrucción en la medida en que los ciudadanos estuvieran dispuestos a mantener las escuelas.

El gobierno de Lira y Ortega tampoco quiso responder por las escuelas de las fincas rústicas. Comprometió a los dueños o arrendatarios para sostener una escuela en la que asistieran todos los niños dependientes de las fincas. ${ }^{29}$ Esta disposición se quedó a medias, ya que no especificaba que se tendría que "sostener" a una escuela. Esto significaría muchas cosas, como la construcción de un local, la inversión en libros y útiles o el pago de los preceptores.

\section{Desplazamiento de la gestión local (1882-1898)}

Los gobiernos estatales fortalecieron a una figura que llevó a la sociedad al borde de la crisis y los alertó a la revolución: Porfirio Díaz. Mariano Grajales, primer gobernador porfirista (enero de 1881 a julio de 1884), era un hacendado conservador de Tlaxco que tendió a centralizar el ramo educativo en el estado. Fue el segundo gobernador ${ }^{30}$ procedente de los municipios más conservadores de Tlaxcala (Rendón, 1993: 45), y con seguridad contó con el apoyo de los hacendados para llegar a la gubernatura. Fue durante el periodo de Grajales cuando se reestructuraron los fondos de instrucción pública y la redistribución de los recursos destinados a las escuelas. Además de facultar al prefecto político para manejar una parte de los fondos de instrucción, dispuso que el estado destinara anualmente cierta cantidad a la educación; de esta manera, el gobierno hizo explícita su participación en el financiamiento de las escuelas.

Grajales cambió la estructura de los organismos educativos locales. La Ley y el Reglamento de instrucción primaria de 1882 incorporaron con mayor fuerza a los políticos en la "dirección de la enseñanza en todo el estado". ${ }^{31}$ Para ello, el gobierno eliminó a las "Juntas Directivas de Instrucción Primaria" y fundó los "Consejos de Instrucción Pública".

\footnotetext{
${ }^{28} 1773$, AHET, fondo colonia, siglo XVIII, c.217, exp. 8.

${ }^{29}$ Art. 8, fracción I, Ley de Instrucción primaria de 1868.

${ }^{30}$ El primero fue Antonio Rodríguez Bocardo.

${ }^{31}$ Ley de instrucción primaria de 1882.
} 
Los Consejos se pensaron en tres dimensiones territoriales y en tres jerarquías políticas. El rango más alto correspondía al Consejo Superior de Instrucción Primaria, descrito en esta ley como "director general de todos los establecimientos de enseñanza pública [...], sea el que fuere su carácter, objeto y jerarquía". ${ }^{32}$ El gobernador del estado era el director del Consejo Superior. El Consejo de Distrito, subordinado al Consejo Superior, ${ }^{33}$ tenía jurisdicción sólo en su distrito.

Este Consejo sería encabezado por el prefecto político; el nombramiento del resto de los integrantes (entre ellos un miembro del ayuntamiento) sería, en parte, obra de los ayuntamientos, ya que estos proponían al Consejo Superior al candidato. ${ }^{34}$ El Consejo municipal se limitó a su respectivo municipio. Cabe señalar que este Consejo a veces fue llamado "auxiliar", como una forma de minimizar su jerarquía, tanto política como educativa. ${ }^{35}$ El Consejo municipal fue presidido por el presidente del ayuntamiento. Los demás miembros eran propuestos en terna por los ayuntamientos al Consejo de Distrito. Las poblaciones más pequeñas sujetas a las cabeceras o pueblos sólo aspiraron a poseer un comisionado del ramo, que quedaba sujeto al Consejo municipal..$^{36} \mathrm{El}$ comisionado fue propuesto en terna por el agente municipal. ${ }^{37}$

Grajales reconfiguró la organización económica de los fondos destinados a las escuelas. Estableció tesoreros de los Consejos Municipales, tesoreros de los Consejos de Distrito y tesoreros del Consejo Superior, aparte del prefecto político. A los primeros les tocó recaudar el 6 por ciento anual de los réditos sobre los "antiguos" terrenos de comunidad y las multas a los padres de familia, parientes o tutores y a toda persona que no enviara a los menores a los establecimientos de enseñanza. Los prefectos políticos cobrarían el impuesto personal de 6 l/4 de centavos. El Consejo Superior recibiría las cantidades que el estado destinara anualmente a la educación. La recaudación del resto de los fondos (el 25 por ciento del importe mensual de todos los ingresos de los ayuntamientos; el cobro sobre "la propiedad, usufructo o uso de fincas rústicas y urbanas procedentes de manda pía o de cualquier origen destinadas a la instrucción", "las donaciones que se hicieren en especie o en dinero y que se invertirán precisamente en su objeto, según la voluntad del donante"; una "manda forzosa con el mínimum de un peso y el máximo de diez y que se cobrará por toda sucesión ex testamentaría o ab intestado y la mitad de las multas que se impongan por todas las autoridades del Estado) correspondió a los tesoreros de los Consejos de Distrito".38

\footnotetext{
32 Art. 25, Reglamento de la Ley de instrucción primaria de 1882.

${ }^{33}$ Art. 26, Reglamento de la Ley de instrucción primaria de 1882.

${ }^{34}$ Art. 8, Ley de instrucción primaria de 1882.

${ }^{35}$ Art. 4, Ley de instrucción primaria de 1882.

${ }^{36}$ Art. 4, Ley de instrucción primaria de 1882.

${ }^{37}$ Art. 8, Ley de instrucción primaria de 1882.

${ }^{38}$ Art. 47 al 53, Reglamento de la Ley de instrucción primaria de 1882
} 
Al considerar la estructura político-económica que armó Mariano Grajales, es claro que en los municipios quedaba muy poco dinero. La mayoría de los recursos se concentraban en las cabeceras de los distritos, sedes de los prefectos políticos. Además, con la extracción del 25 por ciento de los ingresos de los municipios, al ser una orden impuesta por el gobierno, restaba autonomía hacendaria a los ayuntamientos, los cuales no tuvieron suerte con las decisiones sobre la inversión de sus escuelas, tampoco con la concentración, control y distribución del dinero de éstas. La Ley de instrucción primaria de 1882, en el artículo 17, expone que en las tesorerías de cada distrito se haría la distribución de los fondos, "debiendo los municipales acudir a su respectiva cabecera para enterar sus sobrantes si los tuvieran o para reclamar lo que les faltare".

Por su parte, el artículo 32, fracción 5, del Reglamento de la Ley de instrucción primaria de ese mismo año explicita que a los Consejos de Distrito les correspondía llevar en su oficina la cuenta de los ingresos y egresos, así como la de "todas las existencias capaces de producir fondos periódicos o accidentales". Antes del 6 de cada mes, los Consejos de Distrito remitirían al Consejo Superior el corte de caja del mes anterior para su registro y aprobación. ${ }^{39}$ Bajo estas normas legislativas, los ayuntamientos quedaron al margen del dinero recaudado para sus escuelas.

El Consejo Superior de Instrucción Pública estaría enterado de todos los fondos destinados a la instrucción, así como del "costo de su sostenimiento y producto que arroja cada localidad" ${ }^{40}$ El gobierno del estado, por medio del Consejo Superior, mantendría una vigilancia constante del dinero que se generaría de los fondos de instrucción. Según el Reglamento de la Ley de instrucción primaria, el Consejo Superior llevaría una cuenta particular por "débito" y "crédito" a cada uno de los distritos, "de todos los fondos destinados o que en adelante se destinaren a la instrucción pública, teniendo por separado un libro auxiliar en donde se anoten todas las escuelas de cada distrito y los fondos particulares de cada localidad". ${ }^{41}$ La vigilancia sobre el dinero que se generaba llegó al extremo de estipularse en el Reglamento de la Ley de instrucción primaria que los Consejos de Distrito investigarían sobre "toda ocultación de fondos de la instrucción pública, dando de sus averiguaciones cuenta oportuna al superior" ${ }^{42}$ Este mismo Reglamento solicitó a los Consejos Municipales "inquirir en su localidad sobre cualquiera ocultación que pueda lastimar los fondos de instrucción pública y exigir de quien corresponda la mayor exactitud en su recaudación y puntualidad en su entrega". 43

\footnotetext{
${ }^{39}$ Art 32, fracción 5 y 6, Reglamento de la Ley de instrucción primaria de 1882.

${ }^{40}$ Art. 31, fracción 3, Reglamento de la Ley de instrucción primaria de 1882.

${ }^{41}$ Art. 31, fracción 4, Reglamento de la Ley de instrucción primaria de 1882.

${ }^{42}$ Art. 32, fracción 9, Reglamento de la Ley de instrucción primaria, 1882.

${ }^{43}$ Art.33, fracción 7, Reglamento de la Ley de instrucción primaria, 1882.
} 


\section{¿Gratuidad?}

En principio, la Ley de instrucción primaria de 1882 reafirmó que la instrucción elemental debiera ser gratuita. Para cumplir con dicho precepto, según el profesor Antonio P. Castilla, crítico de las leyes, escribió en el periódico oficial de ese año que el gobierno se valió del "tributo" de medio real "señalado como el principal recurso para el sostenimiento de las escuelas". Antonio P. Castilla expresó que esta contribución "no es nueva [...] ni injusta, ni mucho menos onerosa para todo ciudadano honrado que tenga conciencia de lo que se debe a sí mismo y a una sociedad culta de que forma parte". La disertación de Castilla fue pronunciada, según él, en un contexto en que los vecinos de las mayores poblaciones se negaban a pagar el medio real. Casi al final de su discurso, Castilla declaró que "para levantar el estado de su postración" se hiciera pagar el tributo por "voluntad o a la fuerza".44

Según la versión de Antonio P. Castilla, el pago de medio real "de la ley de hoy [...] no es otra cosa que la contribución llamada de Chicontepec de la ley de ayer". ${ }^{5}$ Al referirse a la "ley de hoy", Castilla hablaba de la Ley de instrucción primaria de 1882. Sin embargo, en ningún lado de la ley aparece el medio real.

De los ocho fondos de instrucción pública que se enlistan en la Ley de instrucción primaria de 1882, hubo uno que se reservó para la contribución personal, aunque se trataba del pago de $61 / 4$ de centavos que tenía que hacer todo varón mayor de diez y ocho años y menor de sesenta. ${ }^{46}$ Con los datos de Castilla ${ }^{47}$ no es posible saber en qué documento se asentó la contribución de Chicontepec; lo que sí es probable es que la contribución de Chicontepec seguía siendo financiada por los pueblos.

Un ejemplo sugiere cuáles eran los montos que se manejaban. Según datos cuantitativos, en marzo de 1882, en todo Tlaxcala había 185 personas como "personal de preceptores"; de los cuales 32 eran profesoras y 6 ayudantes, atendiendo a 8,718 alumnos. El total gastado ascendía a $\$ 2,235.50,{ }^{48}$ suma que seguramente cubría sólo los sueldos.

A partir del $1^{\circ}$ de junio de 1882, se ajustaron los gastos de la administración pública. En el nuevo presupuesto a la instrucción, se asignaron \$2,000.00, es decir, sólo 2.3 por ciento de todo el egreso del estado. ${ }^{49}$ Si se compara el dinero fijado por el estado y la cantidad que se invertía en un mes de sueldos, queda una gran suma, entre honorarios y gastos generales de las escuelas que había que cubrir. A los pueblos se les dejó el financiamiento de gran parte

\footnotetext{
44 "Análisis de la Ley de 13 de enero", Órgano oficial de gobierno. El Estado de Tlaxcala, 6 de mayo de 1882. AHET, Fondo Histórico, sección Periódico Oficial del Estado de Tlaxcala.

45 "Análisis de la Ley de 13 de enero", Órgano oficial de gobierno. El Estado de Tlaxcala, 6 de mayo de 1882

${ }^{46}$ Art. 14, fracción I, Ley de Instrucción Primaria del882.

47 "Análisis de la Ley de 13 de enero", Órgano oficial de gobierno. El Estado de Tlaxcala, 6 de mayo de 1882.

48 Órgano oficial de gobierno. El Estado de Tlaxcala, 6 de mayo de 1882.

${ }^{49}$ Órgano oficial de gobierno. El Estado de Tlaxcala, 4 de junio de 1882.
} 
de la instrucción primaria. El gobierno designaba el monto de los honorarios de los maestros de manera totalmente discrecional, de tal forma que hubo gran disparidad entre los sueldos de los maestros que laboraban en diferentes pueblos.

Las reformas educativas introducidas por Mariano Grajales estuvieron vigentes durante el tiempo que duró su mandato, es decir, dos años. A finales de 1884, la revisión de una nueva ley estaba gestándose, al mismo tiempo que se aproximaban las elecciones para gobernador. A partir del 2 de enero de 1885, el ramo educativo quedó sujeto a la Ley de instrucción pública, y al gobernador Cahuanzti le tocó ponerla en práctica.

Próspero Cahuantzi fue un general originario de Tlaxcala, con gran trayectoria militar. En diferentes momentos luchó a favor de Comonfort, Juárez y Díaz. Con el Plan de la Noria (1871) prefirió adherirse a Juárez; bajo la presidencia de Lerdo de Tejada, fue regidor del ayuntamiento de Tlaxcala y en 1876 se inclinó por el Plan de Tuxtepec (Buve, 2010: 87-88). En 1877, intentó ocupar el Ejecutivo del estado; sin embargo, Díaz apoyó a Lira y Ortega, dejando a Cahuantzi una diputación en el Congreso local. Cahuantzi esperó ocho años para llegar al poder en enero de 1885. Desde esta fecha y sin interrupciones gobernó hasta 1911. Cooperaría con Díaz para intentar monopolizar el orden económico, político y educativo. Pudo gobernar veintiséis años el estado gracias al apoyo de Díaz, de los hacendados del estado y de los prefectos políticos. Además, contaba con el respaldo de los grupos más poderosos de los pueblos, especialmente con los "vecinos principales", la gran mayoría de los cuales eran miembros de los ayuntamientos (Solares, 2016: 76-77). Por ello es importante dar un repaso a las medidas legislativas que impulsó Cahuantzi para centralizar la administración del estado, específicamente las leyes que refieren al orden político y económico.

A diferencia de los gobernadores precedentes, Cahuantzi tuvo un origen modesto. Nació en 1834 en el pueblo de Santa María Ixtulco, municipio de Tlaxcala. Probablemente perteneció a alguna familia indígena o mestiza. Rendón sugiere que Cahuantzi no tenía vínculos con familias nobles, ni indígenas ni mestizas, pues las tierras que poseía las había adquirido y no heredado (Rendón, 1993: 41-42). Fue un hombre "campesino indígena" que supo trabajar la tierra, además de manejar bien las armas. Conocía bien los pueblos del estado, sobre todo los indígenas. Al igual que Lira y Ortega, hablaba español y náhuatl. Los estudios que cursó en la primaria del municipio de Chiautempan le bastaron para poder acceder a la gubernatura, ya que los conocimientos que adquirió posteriormente los hizo por su cuenta. Buve (2010: 87) reconoce que fue un autodidacta.

Durante el breve periodo de transición hacia el prosperato, ${ }^{50}$ los fondos de instrucción pública continuaron igual que en la administración de Mariano Grajales. La excepción fue que los ayuntamientos que pagaban 25 por ciento del importe mensual de todos sus ingresos

\footnotetext{
${ }^{50}$ Término acuñado por Raymond Buve (2010), que se refiere a los años que gobernó Próspero Cahuanzti.
} 
municipales, con la Ley de instrucción pública de 1885 cubrirían sólo el 15 por ciento. Es posible que el importe de los municipios bajara y que algún fondo de instrucción compensara ese faltante del 10 por ciento. El impuesto personal, en cambio, permaneció intacto. El artículo 42, fracción 1, dice que todo individuo, varón, mayor de diez y ocho años y menor de sesenta pagaría mensualmente 6 1/4 centavos, "no exceptuando por la presente Ley".

La creciente centralización de la educación en manos del estado se hace visible en las nuevas funciones de la Tesorería General del estado que anteriormente sólo llevaba asuntos financieros, pero no incidía en el ramo de instrucción pública. La Ley de instrucción pública de 1885 es muy explícita en la desaparición de la Tesorería del Consejo Superior, así como el de los consejos distritales y municipales. En el artículo 1 transitorio se lee:

El tesorero del Consejo Superior de Instrucción Pública y los tesoreros de los Consejos de Distrito y de los municipios, al cesar en sus cargos, enterarán desde luego en Tesorería General las cantidades que resulten existentes en su poder, previa la liquidación de cuentas que todos deberán rendir ante dicha oficina a la que entregarán los libros y documentos relativos a dichas liquidaciones. ${ }^{51}$

A partir de entonces, la Tesorería General cobraría los impuestos y demás fondos de instrucción pública por medio de los recaudadores de rentas ${ }^{52}$ quienes, dentro de la política y las finanzas, eran de los más importantes; en cada distrito, junto con el juez de primera instancia y el prefecto político les tocaba el cuidado y la vigilancia de la instrucción primaria. ${ }^{53}$ En la hacienda pública cobraban las rentas del estado en su respectiva jurisdicción, en pocas palabras, eran empleados de la Tesorería General. ${ }^{54}$

La misma tesorería "se encargaría de la contabilidad de los fondos y de su distribución". ${ }^{55}$ Bajo este nuevo esquema de financiamiento, los municipios perdieron el control total de los fondos de instrucción, por lo menos de los impuestos por el estado. La Tesorería General, por ejemplo, haría los pagos directos de todos los gastos concernientes a la instrucción pública. Por si fuera poco, los ayuntamientos, o por lo menos el presidente municipal, rompió el vínculo con los profesores a razón de que la Tesorería General pagaría "directamente" los sueldos de los preceptores. ${ }^{56} \mathrm{~A}$ su vez, ésta tendría una sección de instrucción pública dedicada especialmente a la contabilidad de este ramo, anotando los ingresos y fondos que le corresponden. ${ }^{57}$

\footnotetext{
${ }^{51}$ Art. transitorio, Ley de instrucción pública de 1885.

52 Art. 45, Ley de instrucción pública de 1885

${ }^{53}$ Art. 24, Ley de instrucción pública de 1885.

54 Ley de Hacienda, 1885.

55 Art. 46, Ley de instrucción pública de 1885.

${ }^{56}$ Art. 46, Ley de instrucción pública de 1885.

${ }^{57}$ Art. 46, Ley de instrucción pública de 1885.
} 
El intento del gobierno por controlar el dinero en una tesorería general tuvo una excepción: los prefectos políticos continuarían recaudando la contribución personal, aunque de la cantidad recaudada se tenía que rendir cuenta a la Tesorería General.

Al mismo tiempo, el artículo 13 de la Ley de instrucción pública de 1885 reafirmó que las personas que tuvieran bajo tutela a un niño en edad escolar, estaban obligadas a proporcionar instrucción en las escuelas oficiales, particulares o en lo privado. A los padres de familia no les quedó más que enviar a sus hijos a las escuelas. Si el gobierno forzaba a las familias a instruirse, era de suponer que debía de comprometerse a tener suficiente caudal para cubrir las necesidades mínimas que requería una escuela. Ricardo Rendón (2005: 92) afirma al respecto que, para financiar las obras públicas, entre estas la educación, Cahuantzi decidió incrementar las contribuciones fiscales y su eficiente recaudación. Para acercarse a la propuesta de Rendón es indispensable acudir a la Ley de Hacienda del propio Cahuantzi.

Próspero Cahuantzi fue el primer gobernador de Tlaxcala que trasladó los fondos de la instrucción pública a las leyes hacendarias, como parte de la hacienda pública y no como un asunto exclusivo del ramo educativo ni municipal. En 1888, es decir, apenas a los tres años de que Cahuantzi ocupara la gubernatura, se incorporaron los fondos de instrucción pública en la Ley de Hacienda. ${ }^{58}$

Este cambio fue retomado en la Ley de Hacienda de 1897, idéntica (en el ramo educativo) a la de 1888. Analizaré ésta por ser más cercana a las reformas que realizó el gobernador a la legislación educativa. En la Ley de Hacienda de 1897, los fondos de instrucción fueron nueve, pero el que soportó los gastos educativos se centró en los ocho centavos que tenía que pagar todo varón desde la edad de diez y ocho años hasta los sesenta. Éste es el mismo impuesto personal que todavía en la Ley de instrucción pública de 1885 era de 6 1/4 de centavos. Las otras fuentes importantes fueron el 15 por ciento del importe mensual de todos los ingresos de los fondos municipales y el "producto del 6 por ciento anual que por réditos satisfacen los dueños de los antiguos terrenos que antes eran de comunidad de los pueblos". Además de las multas que imponga el Reglamento de la instrucción primaria de 1898, entre éstas las infracciones que se les impuso a los tutores que no enviaran a los niños en edad escolar a las escuelas..$^{59}$

El manejo de los ingresos de la hacienda pública recaería en la Tesorería General, los recaudadores de rentas y los prefectos. El artículo 138 de la Ley de Hacienda de 1897 estableció que los "impuestos y demás fondos destinados al sostén y fomento de la instrucción pública" quedarían bajo la "dirección y responsabilidad" del tesorero general, quien cuidaría con entera separación de las rentas generales que hagan el cobro de aquéllos las oficinas recaudadoras de los distritos foráneos.

\footnotetext{
${ }^{58}$ Ley de Hacienda, 1888, AHET, sección Folletería, c. 10, núm. 267.

${ }^{59}$ Art. 95, Reglamento de la instrucción primaria de 1898.
} 
Además, la Tesorería General haría la "contabilidad y distribución" de los fondos de instrucción pública, haciendo directamente los pagos de los sueldos de los profesores "y en general de todos los gastos concernientes al ramo". 60 Los recaudadores de rentas se encargaron de cobrar los fondos de instrucción, a excepción del impuesto personal, el cual, como ya era regla, recayó en el prefecto político. ${ }^{61}$

La administración municipal de los fondos casi fue anulada. El artículo 129 de la Ley de Hacienda de 1879 sólo dice que los tesoreros municipales "enterarán" en las recaudaciones de rentas el 15 por ciento de los ingresos del mes anterior. En esta ley, y en las sucesivas que decretó Cahuantzi, los ayuntamientos no tuvieron una participación.

En cuanto a la intervención del estado en el sostenimiento de las escuelas, en la lista de los fondos de instrucción pública no hay uno que indique que el estado le tuviera asignada una partida. ${ }^{62}$ Más bien se apropió del manejo de los fondos preexistentes, sobre todo para pagar al personal de las escuelas. En los Presupuestos se especificaba cuánto dinero destinaba el estado a cada escuela. En los expedidos por Cahuantzi, se detalla el monto que se asignaba a cada maestro por pago de servicios.

Oficialmente, el gobierno sólo se comprometía a invertir en los sueldos de los maestros ${ }^{63}$ (según el presupuesto). El resto de los gastos, según Rendón (1993: 244), fue cubierto por el impuesto personal. El 6 por ciento que por réditos debían pagar los dueños de los terrenos adjudicados y el 15 por ciento de los ingresos municipales.

Aparte de los tesoreros, la Ley de Hacienda regulaba la injerencia de los prefectos políticos en el manejo del fondo de instrucción pública. Aunque los ayuntamientos seguían elaborando los presupuestos y planes de arbitrios, la única vía para que éstos fueran aprobados por la cámara del estado era a través de los prefectos políticos, quienes tenían la "facultad" de "revisar y hacer que se corrijan" los presupuestos y planes "para elevarlos, por conducto del Superior Gobierno" al Congreso. ${ }^{64}$ Una vez aprobados los presupuestos, los prefectos harían que los ayuntamientos invirtieran los fondos conforme a los presupuestos, ${ }^{65}$ así como "cuidar" que se ejercieran los recursos para cubrir los gastos indispensables de las municipalidades.

El dominio sobre los municipios se reafirmó con las visitas del prefecto, "siempre que lo crea conveniente", a las tesorerías municipales, con el objetivo de examinar las cuentas y

${ }^{60}$ Art. 140, Ley de Hacienda de 1897, sección Folletería.

${ }^{61}$ Art. 141, Ley de Hacienda de 1897, sección Folletería.

${ }^{62}$ Art. 141, Ley de Hacienda de 1897.

${ }^{63}$ Aunque el dinero para los sueldos de los maestros provenía de los fondos.

${ }^{64}$ Art. 6, fracción VI, Ley Reglamentaria del artículo 64 de la Constitución Política del estado, para la administración y régimen interior de los Distritos, 1892, AHET, sección Folletería, c. 18, núm. 526.

${ }^{65}$ Art. 5, fracción, VIII, Ley Reglamentaria del artículo 64 de la Constitución Política del estado, para la administración y régimen interior de los Distritos, 1892. 
cortes de caja. Por si fuera poco, si el tesorero se encontraba en "quiebra" el prefecto estaba facultado para "procurar" que la corporación nombrara a otro, para consignar "al responsable al juez competente". ${ }^{66}$

La Ley Reglamentaria del artículo 64 dice del papel de prefecto político que cuidara que los recaudadores de rentas, de su respectivo distrito, no cobraran más de lo que correspondía, "pudiendo aprenderlos en caso de cualquier abuso [...] y consignarlos al juez competente, sin dejar de hacer efectivo el cobro de la cuota legítima". ${ }^{67}$ Tal parece que Cahuantzi otorgó "facultades" y "deberes" a los prefectos para vigilar cuánto dinero se recaudaba y en qué se gastaba, sin desviar el dinero en otras cosas que no estuvieran permitidas por la Ley de Hacienda. Al respecto, el artículo 5, fracción XVII, exhorta al prefecto a "cumplir exactamente" las prevenciones contenidas en la Ley de Hacienda vigente, según las atribuciones que en éstas se les confiere.

En general, al prefecto político le tocó "velar" porque los fondos del erario no se dedicaran a otro objeto, corrigiendo los "abusos que descubran a este respecto y visar los cortes de caja que se practiquen mensualmente en la recaudación de rentas de su respectivo distrito". 68

Próspero Cahuantzi encontró en el prefecto político su mejor aliado para controlar el capital que arrojaban los pueblos. Se supone que la mayoría de lo recaudado iba directamente al pago de maestros. En la práctica, no se sabe si no era suficiente ese dinero, ya que el impuesto personal pasó de $61 / 4$ de centavos a 8 pesos. ${ }^{69}$

\section{Reflexiones finales}

En este artículo he mostrado que, a raíz del proceso de centralización de la instrucción pública en el estado de Tlaxcala, los municipios perdieron, progresivamente, la posibilidad de financiar sus escuelas: primero, porque las legislaciones porfiristas frenaron la iniciativa local de generar sus propios fondos; en su lugar, quedaron sólo los impuestos desde el estado, del cuál fue el más importante el impuesto personal; segundo, porque en los municipios quedaba poco o nada del dinero recaudado. Todo se supone que llegaba a la Tesorería General y de ahí se destinaba el dinero para las escuelas. Los vecinos continuaron contribuyendo para las escuelas, pero estaba fuera de sus posibilidades decidir en qué se ocupaba ese dinero.

\footnotetext{
${ }^{66}$ Art. 6, fracción V, Ley Reglamentaria del artículo 64 de la Constitución Política del estado, para la administración y régimen interior de los Distritos, 1892.

${ }^{67}$ Art. 6, fracción, XXV, Ley Reglamentaria del artículo 64 de la Constitución Política del estado, para la administración y régimen interior de los Distritos, 1892.

${ }^{68}$ Art. 5, fracción, XIV, Ley Reglamentaria del artículo 64 de la Constitución Política del estado, para la administración y régimen interior de los Distritos, 1892.

${ }^{69}$ Ley de Hacienda, 1888, AHET, c. 10, núm. 264.
} 
Parece contradictorio decir que no había dinero para sostener a las escuelas, cuando, en el caso de Tlaxcala, Próspero Cahuantzi aumentó a 8 pesos el impuesto personal. La mala distribución de los recursos fue una situación que pasó desapercibida por aquellos ${ }^{70}$ que proponían la federalización de la educación por falta de presupuesto de los municipios.

La centralización de la educación elemental, en este caso, se explica por la política fiscal. En la época que va de 1857 a 1898, los liberales hicieron madurar rápidamente un estado que comenzaba a ser autónomo y soberano. Durante esos cuarenta y un años, se decretó una serie de disposiciones que respondieron a la ideología e intereses políticos de un sector muy pequeño de la población tlaxcalteca.

De 1857 a 1882, se reconoció y reconfiguró la gestión educativa local. Por lo menos desde el siglo XVIII, los pueblos y los municipios fundaron y financiaron las escuelas, algunas veces de forma voluntaria. Conocemos ejemplos de cómo los municipios se organizaban para tener dinero para los fondos de instrucción o municipales: Yahuquemecac cobraba impuestos "sobre las carnes, licencias de diversiones de máscara y algunos bailes"; San Bernardino recaudaba las rentas de la extracción de resina, sacas de madera". ".1 En estos años, el gobierno tlaxcalteca abrió la posibilidad a los vecinos y ayuntamientos de fundar fondos de instrucción pública, a pesar de que algunos de esos fondos fueron impuestos desde el estado.

No es casualidad que estas primeras legislaciones las elaboraran quienes provenían de los pueblos indígenas del centro del estado que, por cierto, fue la región donde se gestó años después la Revolución mexicana. Miguel Lira y Ortega es uno de los representantes de este grupo. De origen indígena, siempre creyó en la importancia del municipio en el desarrollo de la educación.

A partir de 1882, las bases legales dieron un giro contrario a la gestión local. Las administraciones que coincidieron con la presidencia de Porfirio Díaz facultaron a los gobernadores y a los prefectos políticos para controlar todos los fondos de instrucción, al mismo tiempo que dejaron que los pueblos cubrieran esos fondos. Fue el impuesto personal el principal recurso, el cual se ocupó principalmente para el pago de sueldos de los maestros.

Durante todo el porfiriato, los prefectos políticos controlaron este impuesto, además, se transformaron en una especie de inspectores que vigilaban cuánto y cuándo ingresaba en las tesorerías municipales, y si había desvío de recursos denunciaban la falta al Poder Judicial.

En la etapa legislativa del prosperato (de 1885 a 1898), los fondos de instrucción dejaron de aparecer en las leyes y reglamentos de instrucción pública, y pasaron a ser interés de la

\footnotetext{
70 Por ejemplo, Justo Sierra, Joaquín Baranda y José Vasconcelos, entre otros.

${ }^{71}$ El Pueblo. Periódico semioficial del gobierno del Estado, 1870. AHET, Fondo Histórico, sección Periódico Oficial del Estado de Tlaxcala.
} 
hacienda pública del estado. Las leyes de haciendas y presupuestos fueron, en su momento, los documentos en los que se sostenían las normas y reglas de las finanzas del ramo educativo.

Para concluir, debo aclarar que este artículo se realizó con el análisis y la interpretación de la legislación educativa y política, por lo que queda pendiente averiguar cómo, en la práctica, la sociedad tlaxcalteca hizo o no suyos los preceptos de estas leyes. Además, hay indicaciones de que los pueblos crearon fondos de instrucción, al margen de las leyes para continuar sosteniendo sus escuelas. Estos cuestionamientos quedan pendientes para un futuro trabajo.

\section{Fuentes}

Archivos

AHT Archivo Histórico de Tlaxcala.

Fondo Revolución y Régimen Obregonista (FRRO): Sección Instrucción Pública y Justicia y Gobernación.

Fondo: Mercedes Meade: Sección Biblioteca.

Fondo: Colonia, siglo XVIII.

Fondo Histórico: secciones Periódico Oficial del Estado de Tlaxcala; Estado de Tlaxcala y Folletería.

\section{Documentos}

Constitución del Estado de Tlaxcala (1868), Miguel Lira y Ortega, gobernador, El Pueblo. Periódico oficial del gobierno del estado (mayo y junio).

Constitución Política del Estado de Tlaxcala (1857).

Decreto número 5 (1857), Tlaxcala. Textos de su historia. Siglo xix, en Lía García Verástegui y María Esther Pérez Salas (coords.), Gobierno del Estado de Tlaxcala/Instituto Mora, Tlaxcala, pp. 395-398.

Ley de Hacienda, 1888. AHET, sección Folletería, c. 10, núm. 267.

Ley de Hacienda, 1897. AHET, sección Folletería.

Ley de instrucción primaria (1868), Miguel Lira y Ortega Gobernador, El Pueblo. Periódico semioficial del gobierno del Estado, mayo de 1868, AHET, Fondo Histórico, sección Periódico Oficial del Estado de Tlaxcala.

Ley de instrucción pública (1885), Próspero Cahuantzi, gobernador, Órgano oficial del gobierno, enero y febrero, AHET, Fondo Histórico, sección Periódico Oficial del Estado de Tlaxcala.

Ley orgánica del poder municipal (1869), Miguel Lira y Ortega, gobernador, AHET, sección Folletería, c. 15, núm. 3.

Ley Orgánica del Poder Municipal (1883), en Leyes Orgánicas y Ordenanzas Municipales. AHET, sección Folletería, caja 15, núm. 3.

Ley reglamentaria del artículo 64 de la Constitución Política del Estado. Para la administración y régimen interior de los distritos (1892), AHET, sección Folletería, c. 18, núm. 526.

Ley y Reglamento de la instrucción primaria (1882), Mariano Grajales, gobernador, AHET, sección Folletería. Reglamento de Instrucción primaria obligatoria en el estado (1898), AHET, sección Folletería, c. 3, núm. 94.

Hemerografía 
El Pueblo. Periódico semioficial del gobierno del Estado Libre y Soberano de Tlaxcala, Tlaxcala.

Bibliografía

Acevedo, Ariadna (2015), "Entre el legado municipal y el avance del gobierno federal: las escuelas de la Sierra Norte de Puebla, 1922-1942", Relaciones. Estudio y Sociedad, vol. 36, núm. 143, pp. 51-84

Acevedo, Ariadna (2006), "El precio del progreso. Los pueblos indios y la financiación de las escuelas en la Sierra Norte de Puebla, 1875-1930", ponencia presentada en el Seminario Permanente de Historia Social de El Colegio de México, 4 de diciembre, México.

Acevedo, Ariadna (2004), "Paying for Progress. Politics, Ethnicity and Schools in a Mexican Sierra", University of Warwick, Departamento de Historia, Reino Unido, tesis de doctorado.

Arnaut, Alberto (1998), La federalización educativa en México, 18891994, El Colegio de México/Centro de Investigación y Docencia Económicas (CIDE), México.

Becerril, René (2013), "Las políticas ilustradas y liberales del financiamiento educativo. Más continuidad que ruptura", en Alicia Civera Cerecedo (coord.), Experiencias educativas en el Estado de México. Un recorrido histórico, El Colegio Mexiquense/Fondo Editorial Estado de México, Zinacantepec, pp. 49-84.

Bustamante, José (2013), Escuelas en tiempo de cambio: política, maestros y finanzas en el valle de Toluca durante la primera mitad del siglo XIx, El Colegio de México, México.

Buve, Raymond (2010), Amores y odios compartidos. Puebla y Tlaxcala, Ediciones de Educación y Cultura/ Benemérita Universidad Autónoma de Puebla, Puebla.

Civera Cerecedo, Alicia (coord.) (2013), Experiencias educativas en el Estado de México. Un recorrido histórico, El Colegio Mexiquense/Fondo Editorial Estado de México, Zinacantepec.

García, Lucía (2013), "Surgimiento de la escuela en el municipio de Toluca: 1819-1863", en Alicia Civera Cerecedo (coord.), Experiencias educativas en el Estado de México. Un recorrido histórico, El Colegio Mexiquense/Fondo Editorial Estado de México, Zinacantepec, pp. 15-49.

García Verástegui, Lía y María Esther Pérez Salas (1991), Tlaxcala. Textos de su historia. siglo XIX, t. 12, Lía García Verástegui (coord.), Gobierno del Estado de Tlaxcala/Instituto Mora, Tlaxcala (Historia regional de México).

Lira y Ortega, Miguel (comp.) (1982), El poder municipal. Breves consideraciones histórico-politicas sobre el origen, naturaleza, importancia, etc. de dicho poder, Coordinación General de Desarrollo Municipal/ Fonapas/Cobierno del Estado de Tlaxcala, Tlaxcala.

Lira y Ortega, Miguel (1965), Historia de la erección del estado de Tlaxcala, Pról. de Ezequiel M. Gracia, Sociedad de Geografía, Historia, Estadística y Literatura de Tlaxcala, México.

Padilla, Antonio (2013), "Voces y actores, espacios y bocetos. La educación elemental en el Estado de México a finales del siglo XIx", en Alicia Civera Cerecedo (coord.), Experiencias educativas en el Estado de México. Un recorrido histórico, El Colegio Mexiquense/Fondo Editorial Estado de México, Zinacantepec, pp. 85-130.

Pardo, María del Carmen (coord.) (1999), Federalización e innovación educativa en México, El Colegio de México, México.

Rendón, Ricardo (2005), Breve historia de Tlaxcala, México, El Colegio de México/Fondo de Cultura Económica/Fideicomiso Historia de las Américas (FHA).

Rendón, Ricardo (1993), El prosperato. Tlaxcala de 1885 a 1911, Siglo xxı/Universidad Iberoamericana, México.

Rockwell, Elsie (2007), Hacer escuela. Hacer estado. La educación posrevolucionaria vista desde Tlaxcala, El Colegio de Michoacán/CIESAS/Centro de Investigación y de Estudios Avanzados, Zamora, Michoacán.

Solares, María de Lourdes (2016), "La centralización de la instrucción pública en Tlaxcala: un análisis de la legislación estatal (1857-1898)", Departamento de Investigaciones Educativas del Cinvestav, Instituto Politécnico Nacional, México, tesis de maestría. 
Tanck de Estrada, Dorothy (2002), "El gobierno municipal y las escuelas de primeras letras en el siglo XVIII mexicano", Revista Mexicana de Investigación Educativa, vol. 7, núm. 15, pp. 257-278.

Tanck de Estrada, Dorothy (1999), Pueblos de indios y educación en el México colonial, 1750-1821, El Colegio de México, México.

María de Lourdes Solares Ramos es profesora de la Escuela de Educación Normal "José Santos Valdés". Egresada de la Maestría en Ciencias, con especialidad en Investigaciones Educativas del Departamento de Investigaciones Educativas del Cinvestav-IPN, su trabajo se ha enfocado en historia y antropología de la educación en los siglos XIX y XX.

Recibido: 17 de noviembre de 2018.

Aceptado: 18 de diciembre de 2018. 